\title{
Urgences
}

\section{Mario Cotté, Variations sur des légendes bicoises, Sherbrooke, Naaman, 1986, 66 p.}

\section{Hélène Chassé}

Numéro 16, mars 1987

D.G. Jones : d'un texte, d'autres

URI : https://id.erudit.org/iderudit/025410ar

DOI : https://doi.org/10.7202/025410ar

Aller au sommaire du numéro

\section{Éditeur(s)}

Urgences

\section{ISSN}

0226-9554 (imprimé)

1927-3924 (numérique)

Découvrir la revue

Citer ce compte rendu

Chassé, H. (1987). Compte rendu de [Mario Cotté, Variations sur des légendes bicoises, Sherbrooke, Naaman, 1986, 66 p.] Urgences, (16), 98-99.

https://doi.org/10.7202/025410ar d'utilisation que vous pouvez consulter en ligne.

https://apropos.erudit.org/fr/usagers/politique-dutilisation/ 
égrener son parcours en syncopes

par solidaritê» (p. 20, je souligne)

Accepter la rêclusion silencieuse, c'est accepter la défaite et inviter les autres à en faire autant; refuser, c'est s'engager dans le «dur plaisir rebelle» d'un combat incertain pour la reconquête de son intégrité. C'est faire à rebours tout le parcours déjã suivi, c'est reprendre ce qu'on avait jeté à la poubelle et reconstruire: reprendre corps: retrouver ses sens et les raviver un à un, explorer les profondeurs du sous-sol pour s'assurer de la vitalité des racines, repasser par la chambre, la cuisine, accéder au grenier des souvenirs pour redonner vie à l'enfance, à ses gestes, à ses rêves, à ses révoltes. Renaître neuve en mai, riche d'un passé à même lequel on s'est reconstruite et d'une sagesse sereine qui nourrit la jeunesse du sang.

Toute intéressante qu'elle soit, cette thématique n'est pas nouvelle en poésie québécoise et ce n'est pas elle qui donne au recueil son originalité. Tout a été dit; c'est la manière de les exprimer qui peut renouveler certaines vérités et c'est par là que Michelle Dubois rếussit à composer un univers original en créant son imagerie propre à même les objets les plus communs qui meublent le quotidien de tant de femmes. Son art consiste à doser parfaitement le lyrisme avec une santé qui permet aux situations les plus tragiques de demeurer soutenables et d'être regardées avec une calme lucidité, en évitant de tomber dans les clichés des dialectiques des féministes exaspérées. C'est cette santé qui confère au discours son caractère attachant, son naturel et sa force de conviction.

J'ai aimé Prendre corps. C'est une oeuvre qui sait faire vibrer et faire réfléchir; une oeuvre qui démontre une grande maturité et une bonne maîtrise de l'écriture, particulièrement dans les parties qui adoptent une forme plus proche de la prose; la parole y est plus libre et personnelle, l'émotion plus forte et le propos plus limpide. J'ai particulièrement apprécié qu'un auteur de la région opte de façon délibérée pour écrire son propre livre sans faire de concessions aux savantes modes bien vues dans les cercles fermés et sans oeillades aux critiques officiels.

Lucien Cimon

\section{Mario Cotté: Variations sur des légendes bicoises, Sherbrooke, Naaman, 1986, 66 p.}

Du temps où Patrice de La Tour du Pin frayait encore avec l'irréalité avant d'entreprendre une aventure théologique à la façon de Saint Thomas, il avait écrit (La quête de joie, Gallimard, 1933): «Tous les pays qui n'ont plus de légende / Seront condamnés à mourir de froid...”.

La Sologne, certes, ne manque ni de forêts, ni d'étangs, ni de tourbières propres à exciter l'imagination populaire. A ce compte, le paysage majestueux du Bic, P.Q. recèle des mystères autrement plus poétiques.

C'est d'abord ce qu'a voulu nous livrer Mario Cotté, amoureux comme pas un des efantômes qui font du saute-mouton avec les nuages" (p. 11), de ces récifs qui bordent la côte, de ces caps aux noms troublants, de cette mer qui écume et de ces islets grugés par l'histoire et les marées. 
Là-dessus, sa plume s'emporte. Il la contrôle à peine. Son inspiration l'exalte. Exactement comme ce qu'il arrive au Grëgoire de son dernier conte: Une disträction légendaire. À trop négliger de voir le précipice, celui-ci y tombe. En meurt-il pour autant? Si. Mais l'oeuvre demeure!

Le plus étonnant chez Mario Cotté est qu'il ne se bat pas avec l'encre.

Dans une époque où toute approche narrative est remise en question, oũ chaque mot, chaque phrase se pèsent et se soupèsent, lui, il pousse l'ampleur à sa préférence. Sorte de courage qui reporte le lecteur/la lectrice à une mode périmée où, à travers un descriptif qui use et abuse d'émotivité expressive, se trouve soudain cet aveu lucide (p. 29): «je vais tenter de raconter... en me gardant bien de laisser courir mon imagination qui a tendance à endolorir la vérité en la torturant d'entorses.»

Ce n'est pas tant la "vérité», dans ce petit livre, qui est «torturée d'entorses». La légende, par définition, tire sa poétique de l'interprétation et, sur ce point, l'auteur ne manque pas d'allant. Au contraire! Qu'il ait choisi d'intituler son recueil «Variations» nette connotation musicale - plutôt que «Variantes» lui confêrait une latitude d'invention qu'il a bellement exploitée. Il évitait ainsi d'être taxé de fantaisiste dans un domaine où de nombreux spécialistes consacrent leur temps à extraire de la tradition orale le rapport le plus immédiat avec ce que nous sommes.

Non, outre le style - quelques-uns diront ampoulé, d'autres désuet ou carrément exacerbé (à plusieurs endroits) - ce bref ouvrage de 66 pages, traitant quand même de huit légendes très bicoises - les deux derniers textes symbolisant les préoccupations de l'auteur - démystifie de manière libre et charmante certaines hantises qui alimentaient les longues conversations de nos ancêtres et qui ne sont pas sans conserver, encore aujourd'hui, un curieux attrait. Qui ne s'est pas demandé ce qui s'était passé à l'île-au-Massacre?... Qui, du Bic, n'a pas entendu parler de La Batoche, de Josaphat La Roupie ou de la sirène de l'îlôt d'Amour?... Avec leur cortège romantique, les légendes ont cela de beau, elles ont la vie coriace!

C'est mine de rien que Mario Cotté réfère à la réalité historique qui est toujours à la base d'une légende. De toute évidence, son souci est ailleurs. Absorbé par ces personnages et ces histoires qui ont marqué son enfance, il s'en sert comme tremplin à un chant plus vaste: du «je» au «vous», en passant par des témoins narrateurs, n'hésitant pas à faire frémir par le récit détaillé d'actes sanglants ou abominables, il se plaît surtout à montrer du Bic - avec un appel à la préservation - tout ce que ce «microcosme de pays» (p. 60) a d'unique, de superbe et d'enchanteur.

Que les éditions Naaman, pour une fois, aient soigné la présentation d'un livre, en attirant les lecteurs avec un objet coloré, lui revenait sans doute de droit.

Dix encres, aux traits rapides, arrondis et sensuels, signées Suzanne Lavoie, illustrent chacun des chapitres de ce recueil. Elles les agrêmentent dans la mesure oũ les sujets abordés par l'auteur se prêtaient à une représentation concrète.

Hëlène Chassé 